\title{
Energy Consumption of Institutional Buildings Considering the Urban Climate in Rome
}

\author{
Massimo Palme ${ }^{1,2}$, Carola Clemente ${ }^{2}$, Serena Baini ${ }^{2}$, Claudia Calice ${ }^{2}$, Agnese Salvati ${ }^{3}$ \\ ${ }^{1}$ Universidad Católica del Norte, Escuela de Arquitectura, Antofagasta, Chile \\ ${ }^{2}$ Università di Roma La Sapienza, DIPDTA, Italy \\ ${ }^{3}$ University Brunel, London, UK
}

\begin{abstract}
Institutional buildings are very important considering the impact on energy consumption of a city. Due to the conditions of operation, the size and the density of occupants, institutional buildings represent a challenge to save energy in both cold and hot seasons. Urban climate influences the building performance, typically reducing thermal demand in winter and increasing in summer. The context is relevant in determining urban heat island effect, shadows, ventilation and in general the thermal environment that surrounds buildings. This paper develops a strategy to estimate the energy penalty obtained by including in building performance simulation the urban effects. Urban Weather Generator v. 4 beta and TRNSYS v. 17 tools are used to obtain base and urban energy demand through the whole year in three cases of study in Rome.
\end{abstract}

\section{Introduction}

Institutional buildings (hospitals, schools, universities, offices) are responsible for about the 50\% energy consumption of the non-residential building sector in many countries (Pérez-Lombard et al. 2008). The half of this consumption refers to HVAC operation, meaning that the accomplishment of thermal requirements in Institutional buildings represents an important part of the global energy consumption of the whole sector (Menezes et al. 2014). In Mediterranean climates, heating or cooling needs are predominant, depending on climatic specific location. In Rome, a little prevalence of heating need has been found (Calice et al. 2017). However, climate change affects the energy requirements of buildings in a way that a shift between heating and cooling needs has to be expected in the near future (Jenkins et al. 2009, Sailor 2014, Santamouris 2014, Toledo et al. 2016). Moreover, urbanization modifies the microclimatic conditions by reducing heating needs and increasing cooling needs under the urban heat island effect. The link between urban and building simulation has been explored in the last years and first methodologies for integrating tools and models are under development. However, multiple effects of urban environment are difficult to be related to standard building performance simulation, because of the time dependent nature of environment that is fast changing, especially regarding ventilation effects. This paper approaches the problem by estimating representative shadows and breezes environments and incorporating the urban microclimate in TRNSYS models.
The novelty respect to similar studies is the use of the shadow mask in BPS to consider the shadows' impact on heating and cooling needs. The shadow mask is designed in order to be coherent with the urban sector parametrization inserted in UWG models. The effect of shadows is normally counteracting the urban heat island intensity, which means that the final thermal need is determined by local conditions such as the surface temperature of the surroundings and the variations in air renovations introduced by urban environment. However, in this paper infra-red environment and air circulation effects changes have been neglected, so only shadows and air temperature increase by UHI intensity are considered.

\section{Methodology}

The paper presents simulation studies conducted using TRNSYS tool on three reference buildings: an office building (ARPA Lazio) and two university buildings: Math building and Chemistry building. Urban weather files are generated using the Urban Weather Generator (UWG) tool (Bueno et al. 2013). To obtain the parameters needed to run UWG simulation, a GIS procedure was used to model the considered urban sectors.

\section{Location of case studies}

Case studies locate in Rome, Italy. Figure 1 shows the emplacements of ARPA Lazio and of Math and Chemistry buildings of Sapienza University. Both emplacements are placed in the city centre, with green spaces near to the analysed areas. Figures 2 and 3 show the buildings' aspect.

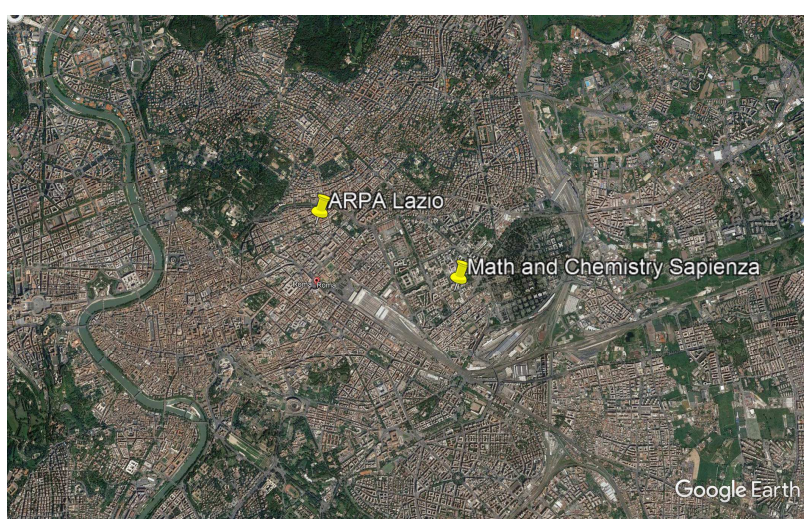

Figure 1: selected locations in Rome 


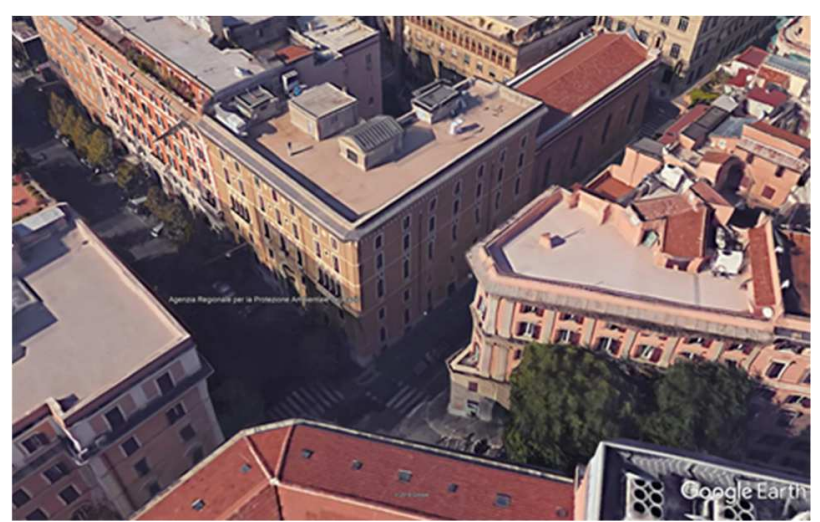

Figure 2: ARPA building

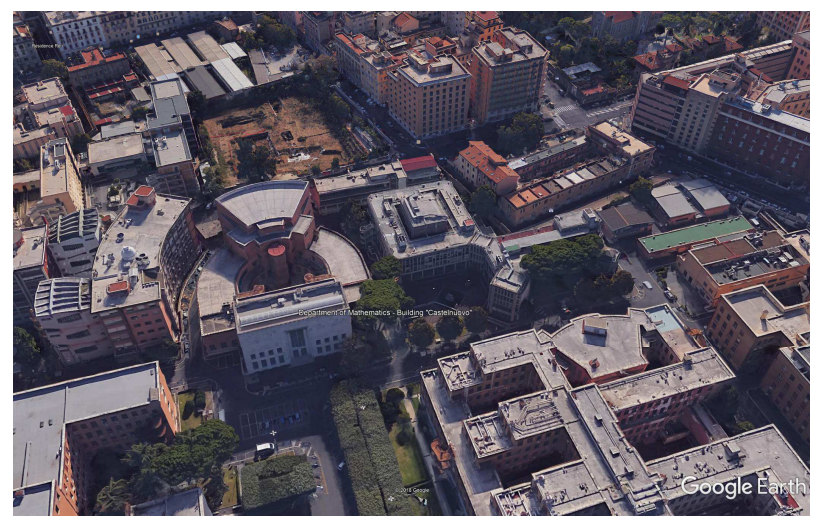

Figure 3: Math and Chemistry buildings

Urban weather files generation

Figures 4 and 5 represent the urban area considered for weather file generation using UWG tool. Table 1 resumes the values used for parametric interpretation of urban areas.

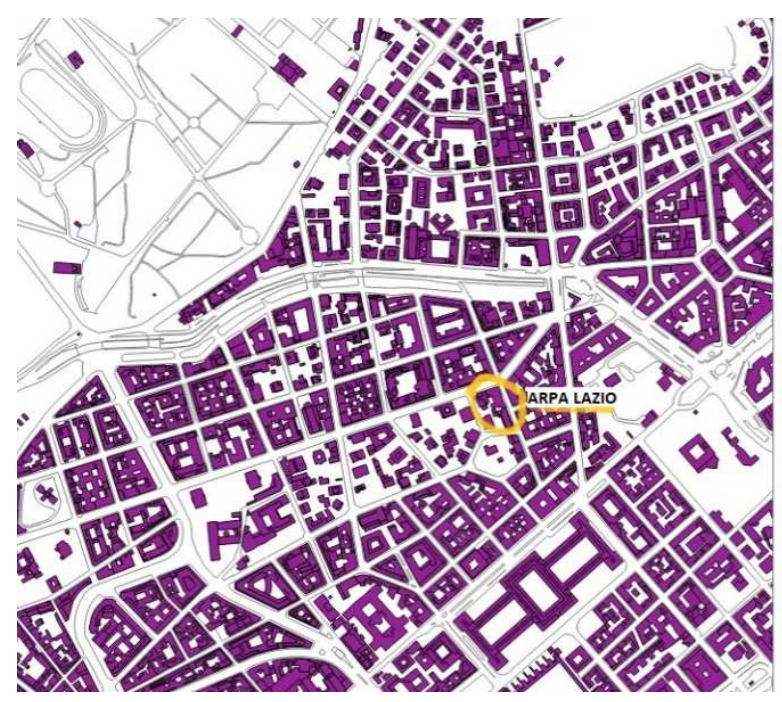

Figure 4: Urban area surrounding ARPA building

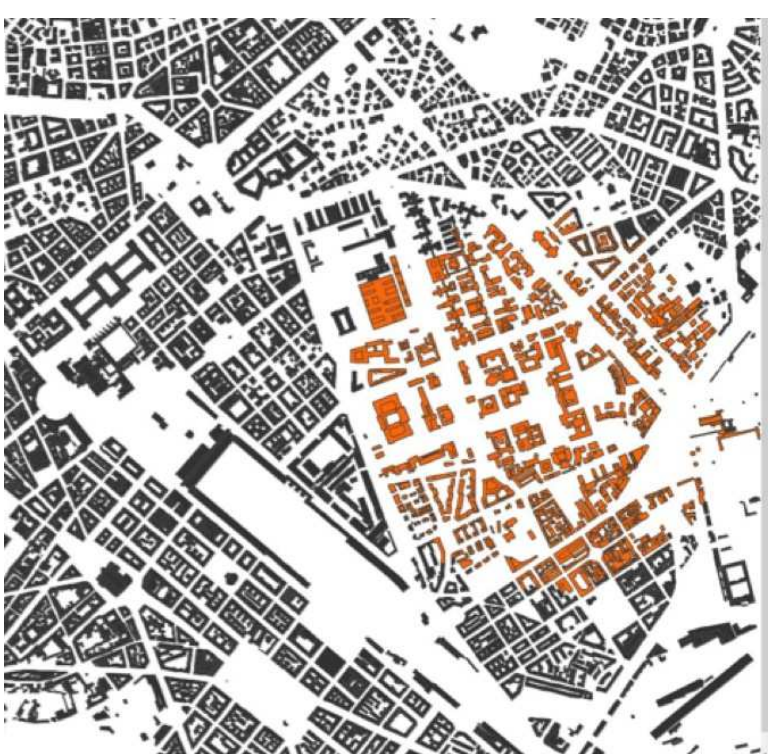

Figure 5: University campus area

Table 1: Urban weather generation parameters

\begin{tabular}{|c|c|c|}
\hline & $\begin{array}{c}\text { ARPA } \\
\text { Lazio }\end{array}$ & $\begin{array}{c}\text { Sapienza } \\
\text { Campus }\end{array}$ \\
\hline \multicolumn{3}{|l|}{ Reference site } \\
\hline Latitude $\left({ }^{\circ}\right)$ & \multicolumn{2}{|c|}{41.47} \\
\hline Longitude $\left({ }^{\circ}\right)$ & \multicolumn{2}{|c|}{12.41} \\
\hline \multicolumn{3}{|l|}{ Urban Area } \\
\hline Site coverage (-) & 0.45 & 0.29 \\
\hline Façade ratio $(-)$ & 1.66 & 0.87 \\
\hline Average height (m) & 20.1 & 16.4 \\
\hline Tree coverage $(\%)$ & \multicolumn{2}{|c|}{12} \\
\hline Anthropogenic heat $\left(\mathrm{W} / \mathrm{m}^{2}\right)$ & \multicolumn{2}{|c|}{8} \\
\hline \multicolumn{3}{|l|}{ Buildings } \\
\hline Day-time heating set-point $\left({ }^{\circ} \mathrm{C}\right)$ & \multicolumn{2}{|c|}{18} \\
\hline Night-time heating set-point $\left({ }^{\circ} \mathrm{C}\right)$ & \multicolumn{2}{|c|}{15} \\
\hline Day-time cooling set-point $\left({ }^{\circ} \mathrm{C}\right)$ & \multicolumn{2}{|c|}{26} \\
\hline Night-time cooling set-point $\left({ }^{\circ} \mathrm{C}\right)$ & \multicolumn{2}{|c|}{35} \\
\hline Heat released to the canyon $(\%)$ & \multicolumn{2}{|c|}{50} \\
\hline \multicolumn{3}{|l|}{ Elements } \\
\hline Wall materials and thickness & \multicolumn{2}{|c|}{ Bricks $43 \mathrm{~cm}$} \\
\hline Wall albedo (-) & 0.25 & 0.35 \\
\hline Roof materials and thickness & \multicolumn{2}{|c|}{ Insulated $38 \mathrm{~cm}$} \\
\hline Roof albedo (-) & 0.25 & 0.25 \\
\hline Road albedo (-) & 0.08 & 0.08 \\
\hline \multicolumn{3}{|l|}{ Rural } \\
\hline Albedo & \multicolumn{2}{|c|}{0.2} \\
\hline Emissivity & \multicolumn{2}{|c|}{0.95} \\
\hline Vegetation coverage & \multicolumn{2}{|c|}{48} \\
\hline
\end{tabular}

Urban morphological parameters have been obtained from equations (1) (2) and (3):

$$
\text { Site coverage }=\frac{\sum A_{\text {buildings }}}{A_{\text {site }}}
$$

$$
\text { Façade ratio }=\frac{\sum p \times h_{\text {weighted }}}{A_{\text {site }}}
$$


Table 2: Building Performance simulation parameters

Urban weather generator couples an atmosphere model (boundary layer) and a building model based on Energy Plus (Bueno et al., 2011 and 2012) to obtain a modified weather file in epw format from a base file (normally referred to airports meteorological stations - in this case, Rome Ciampino airport). In the UWG beta version used, anthropogenic heat produced in the street was considered as a fixed value of $8 \mathrm{~W} / \mathrm{m}^{2}$ (Pigeon et al. 2007). Sensitivity studies (Salvati et al. 2016, Palme et al., 2017 and 2018) put in evidence that most important parameters to be assessed in details to have realistic results in Mediterranean climates are the urban morphology, the albedo values and the anthropogenic heat generation. So, the most important limitation of the urban weather generated for this study is the anthropogenic heat estimation. However, beta version had the advantage to permit the insertion of user defined buildings' materials and operation data.

\section{Building performance simulation}

Once urban weather file has been generated, a simulation set is conducted to obtain heating and cooling demand for base weather and urban weather of each area. TRNSYS studio was used to model building performance simulation and different types has been used for different physical phenomena involved, namely:

- Type 56, for multy-zone building definition

- Type 31e, for psycometric properties calculation

- Type $69 \mathrm{~b}$, for fictive sky temperature calculation

- Type 67, for shadow masks definition

- Type 15-3, for weather data reading in epw format

- Type $65 \mathrm{c}$, for results visualization and writing

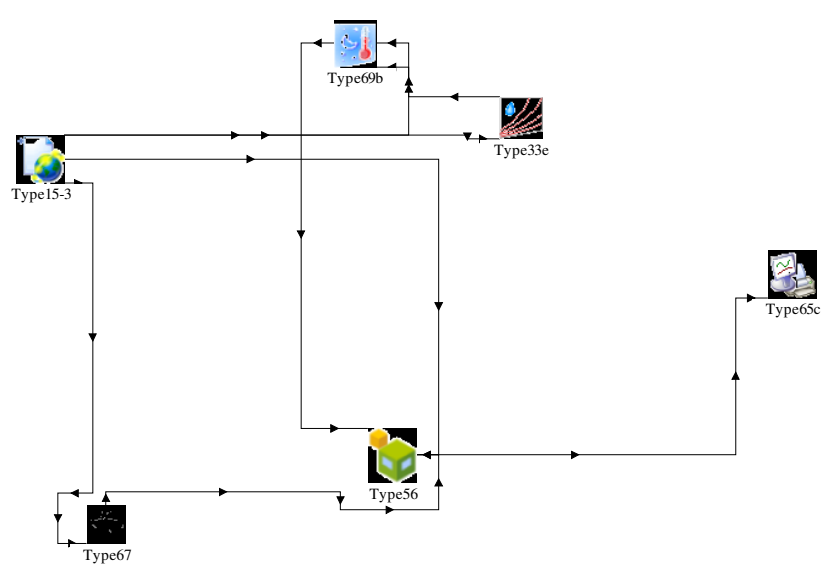

Figure 6: TRNSYS Studio model

\begin{tabular}{|c|c|c|c|}
\hline & ARPA & Math & Chemistry \\
\hline Operation & \multicolumn{3}{|c|}{50} \\
\hline Occupancy $\left(\mathrm{m}^{2} /\right.$ person $)$ & \multicolumn{3}{|c|}{0.2} \\
\hline Occupancy schedule & \multicolumn{3}{|c|}{18} \\
\hline Infiltration $\left(\mathrm{h}^{-1}\right)$ & \multicolumn{3}{|c|}{22} \\
\hline Ventilation $\left(\mathrm{h}^{-1}\right)$ & \multicolumn{3}{|c|}{} \\
\hline Heating set-point & \multicolumn{3}{|c|}{} \\
\hline Cooling set-point & \multicolumn{3}{|c|}{} \\
\hline Internal gains $\left(\mathrm{W} / \mathrm{m}^{2}\right)$ & 5 & 4763 \\
\hline Total floor area $\left(\mathrm{m}^{2}\right)$ & 3590 & 5385 & 47.3 \\
\hline Envelope & 1.5 & 1.5 & 1.2 \\
\hline U wall (W/m $\left.{ }^{2} \mathrm{~K}\right)$ & 1.5 & 1.3 & 2.5 \\
\hline U roof & 3.0 & 2.7 & 5.8 \\
\hline U floor & 5.1 & 5.4 & 40 \\
\hline U windows & 18 & 25 & \\
\hline Glazed surface $(\%)$ &
\end{tabular}

Table 2 resumes the values considered for buildings' envelope and operational parameters. As mentioned in the introduction, institutional buildings are especially important for building sector energy consumption, because of the high occupation rate and of the comfort range that is less variable respect to residential spaces. For this reason, we have considered a thermostat setting of 22 degrees Celsius during occupation hours through the whole year. Shadow mask definition is done by considering a regular array that fit space with the same density used in UWG calculation (figure 7).
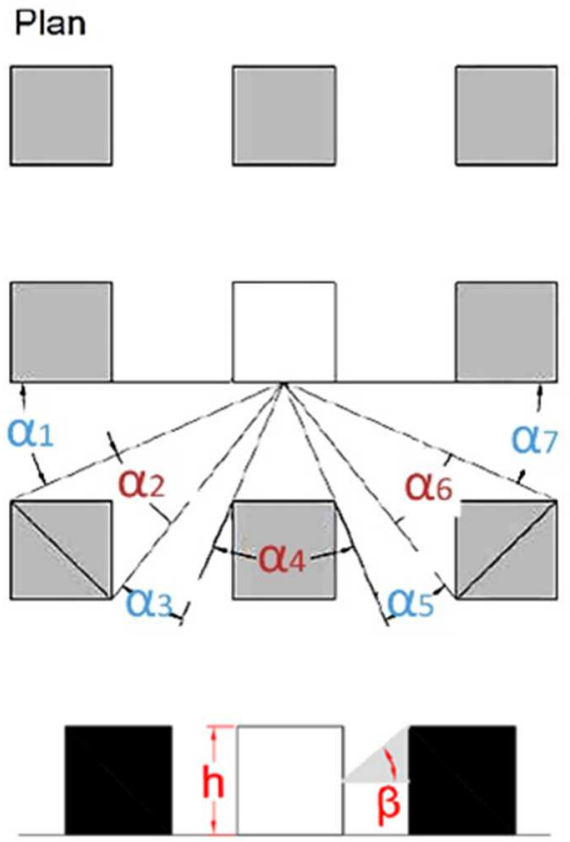

Elevation

Figure 7: shadow array generation 
Table 3: Shadows angles values

\begin{tabular}{|c|c|c|}
\hline & Campus & ARPA \\
\hline $\boldsymbol{\alpha}_{1}=\boldsymbol{\alpha}_{7}$ & $42^{\circ}$ & $32^{\circ}$ \\
\hline $\boldsymbol{\alpha}_{2}=\boldsymbol{\alpha}_{6}$ & $26^{\circ}$ & $18^{\circ}$ \\
\hline $\boldsymbol{\alpha}_{3}=\boldsymbol{\alpha}_{5}$ & $0^{\circ}$ & $30^{\circ}$ \\
\hline $\boldsymbol{\alpha}_{4}$ & $44^{\circ}$ & $24^{\circ}$ \\
\hline $\boldsymbol{\beta}$ & $21^{\circ}$ & $32^{\circ}$ \\
\hline
\end{tabular}

Equations (4) and (5) are used to obtain the angular values of the array (Palme and Salvati, 2018). Table 3 resumes obtained values for analysed cases.

$$
\begin{aligned}
& \text { site coverage }=\frac{a^{2}}{\left(\frac{a}{2}+\frac{b}{2}\right)^{2}} \\
& \text { fachade ratio }=\frac{4 a h}{\left(\frac{a}{2}+\frac{b}{2}\right)^{2}}
\end{aligned}
$$

\section{Results and discussion}

Figures 8 to 11 show the urban heat island intensity in the location of ARPA building (via Boncompagni) and in the University Campus of la Sapienza, where both Math and Chemistry buildings are placed. UHI in Rome seems to be higher during the night, in accordance with the basic formulation of the phenomenon (Howard, Oke).

UHI intensity is also found to be higher in winter than in summer, suggesting that reduction in heating should be higher than increase in cooling demand for considered buildings. University Campus shows some irregularities in UHI intensity, such as negative UHI during some days, probably due to the effect of shadows. Table 4 resumes HDD and CDD for airport station and for UWG generated weather file in both urban locations.

Table 4: Heating and Cooling Degrees Day (18,3 Celsius Degrees based)

\begin{tabular}{|l|l|l|l|}
\hline & $\begin{array}{l}\text { Ciampino } \\
\text { Airport }\end{array}$ & $\begin{array}{l}\text { ARPA } \\
\text { sector }\end{array}$ & $\begin{array}{l}\text { University } \\
\text { Campus }\end{array}$ \\
\hline HDD & 1560 & 1240 & 1425 \\
\hline CDD & 663 & 985 & 765 \\
\hline
\end{tabular}

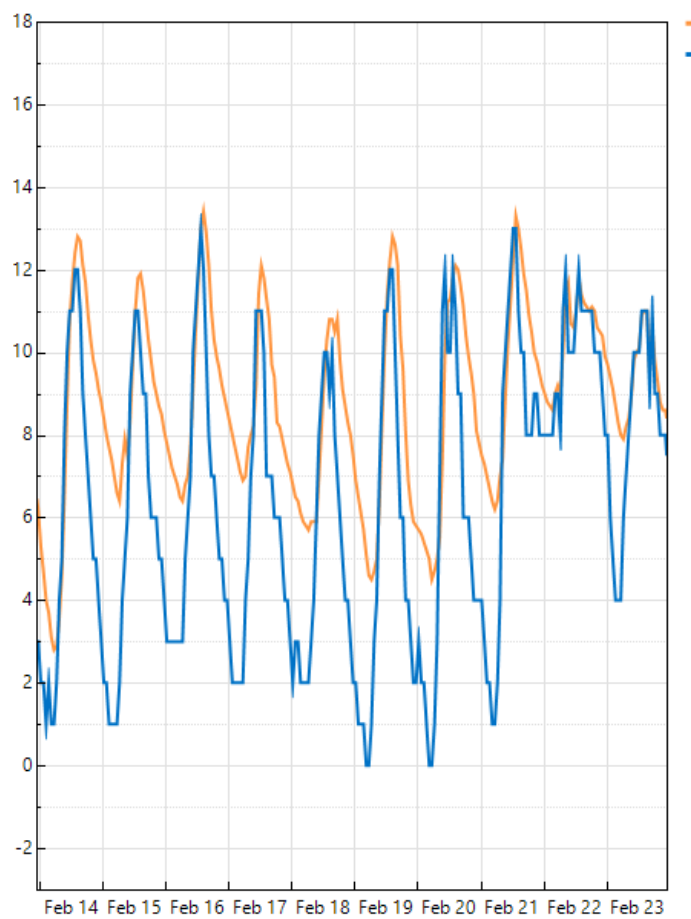

- $B O N C O M P A G N_{201}$ - $\mathrm{CIAMPINO}_{2013 \mathrm{COR}}$

Figure 8: winter UHI intensity ARPA sector

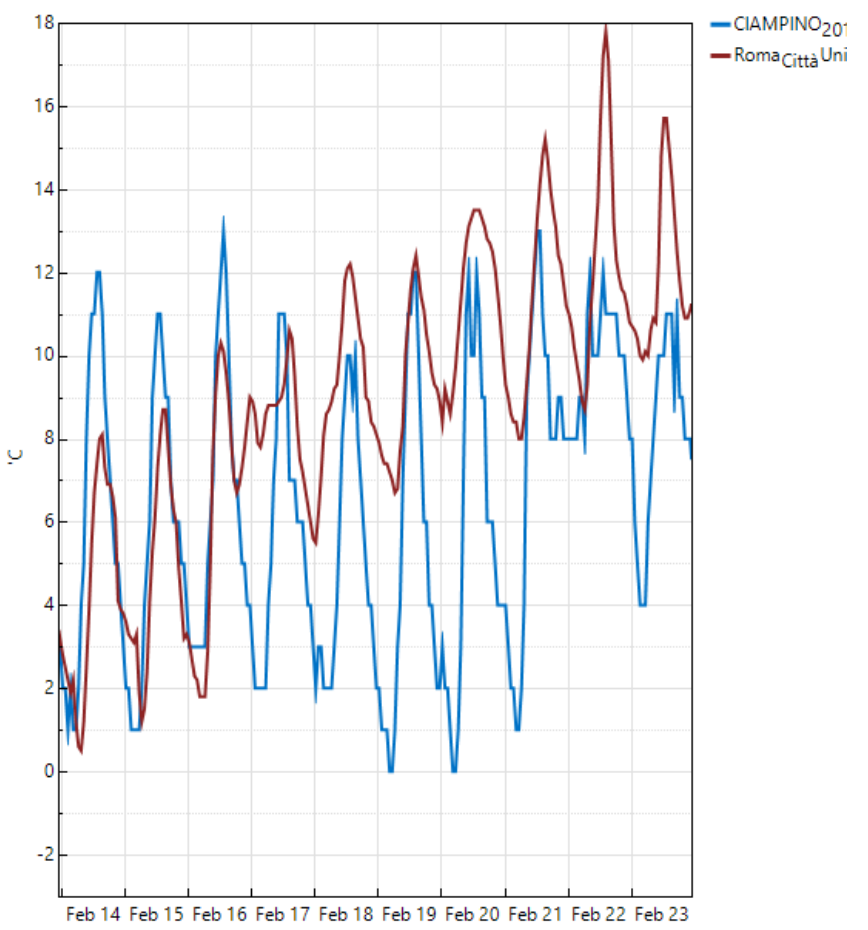

Figure 9: winter UHI intensity Sapienza Camus 


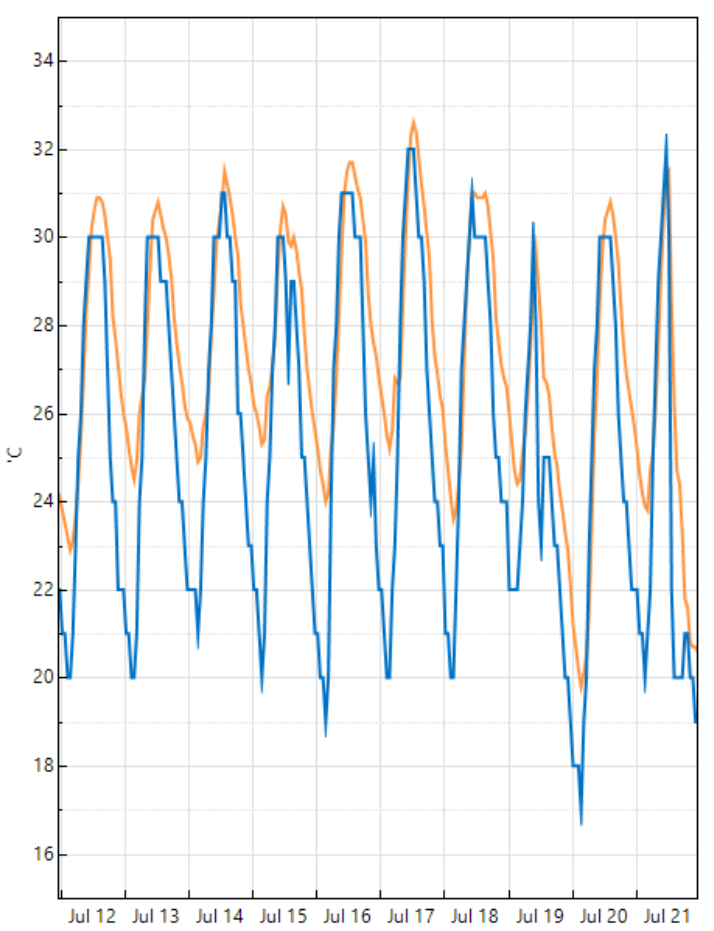

Figure 10: summer UHI intensity ARPA sector

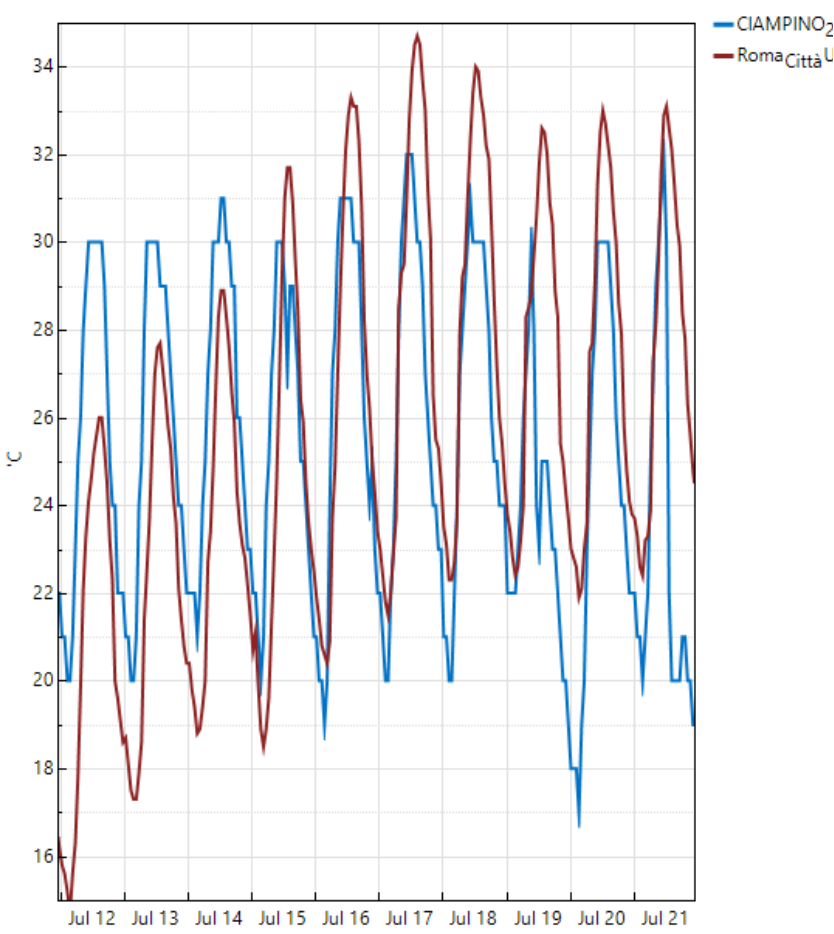

Figure 11: summer UHI intensity Sapienza Campus

In the case of Chemistry building, the glazed surface and the higher internal gains considered in simulation lead to a different situation: cooling demand is prevalent in the base case and increases in the urban case.
In all considered cases the use of the urban weather file in simulation reduces the heating demand results and increases the cooling demand results. It is an expected result, because o the increase in temperatures in the urban weather file. However, the UHI intensity analysis suggested that heating should have decreased more than cooling increased, resulting in a net energy demand decrease. Obtained values show a different behaviour: the total energy demand increases in all cases (by a small amount). Figures 12-14 show the heating and cooling needs.

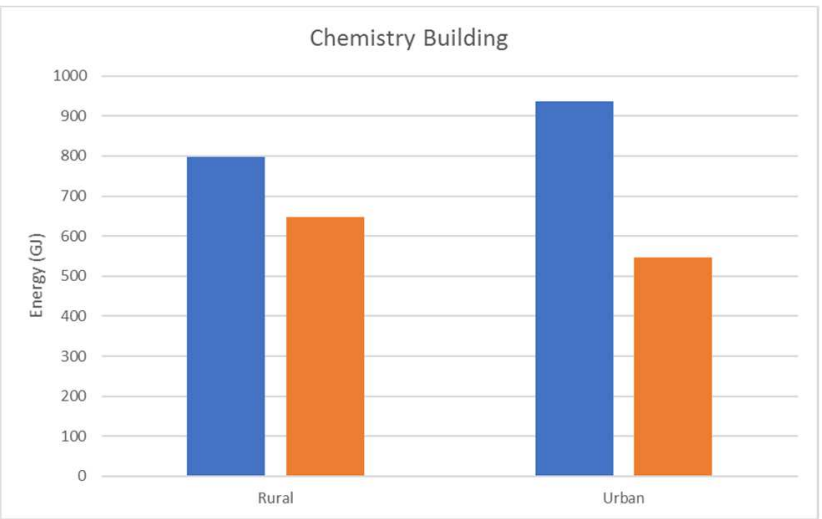

Figure 12: heating and cooling demand, Chemistry building

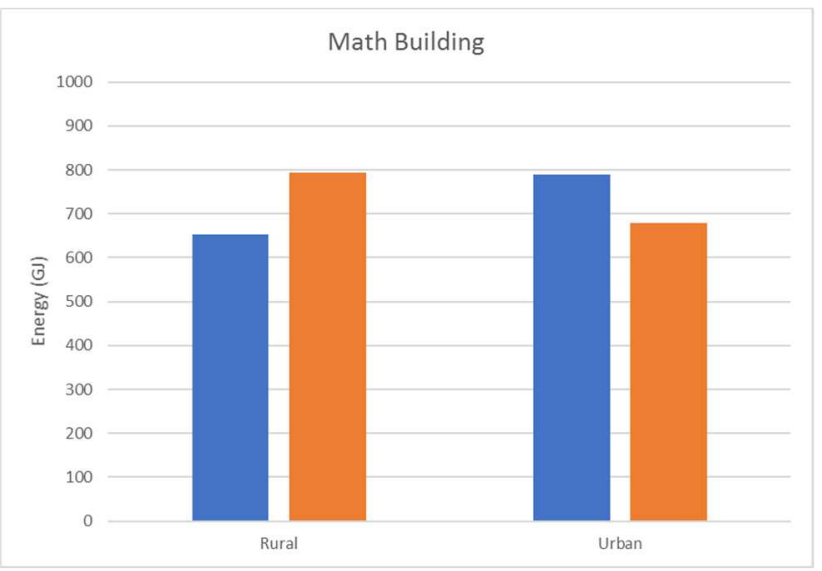

Figure 13: heating and cooling demand, Math building

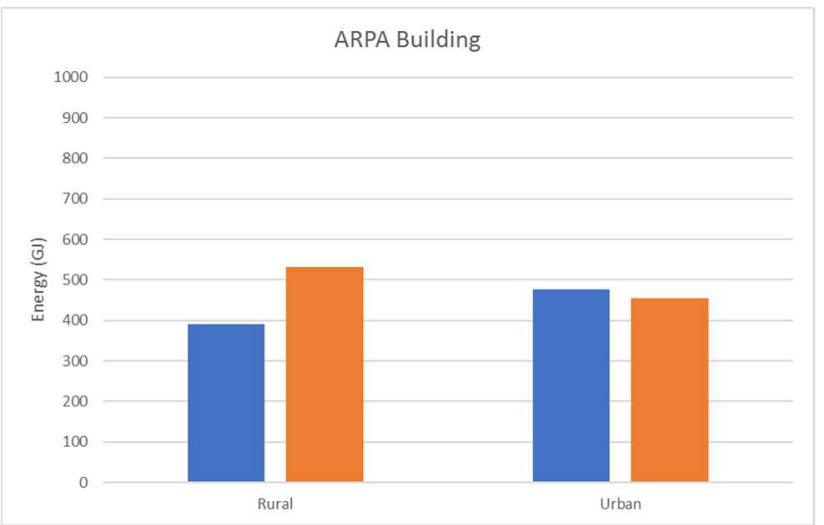

Figure 14: heating and cooling demand, ARPA building 


\section{Conclusion}

This paper evaluated the energy consumption of three institutional buildings in Rome, considering the urban climate effects on the thermal demand, especially the Urban Heat Island intensity. Results suggest that a "shift" between heating and cooling simulation results has to be expected when using a corrected urban weather file (in this case, obtained using Urban Weather Generator). A small net energy demand amount (global penalty) has also been found. This result suggest that urban weather files have to be used in building performance simulation. This result also indicates that probably the energy use of the University Campus is incorrect (or at least very different from simulation assumptions). Heating consumption can be reduced if a rational use of thermostat regulation is applied. The high heating consumption of the entire Campus should be regarded as user-behaviour dependent (different operation temperatures and schedules respect to simulation).

\section{Acknowledgement}

This work received the support of the Visiting Researcher programme of Sapienza University of Rome.

\section{References}

Bueno, B., Norford, L., Pigeon, G., Britter, R. (2011). Combeining a detailed building energy model with a physically-based urban canopy model. Boundarylayer metereology 140(3), 471-489

Bueno, B., Norford, L., Pigeon, G., Britter, R. (2012). A resistance-capicitance network for the analysis of the interactions between the energy performance of buildings and the urban climate. Building and Environment 54, 116-125

Bueno, B., Norford, L., Hidalgo, J., Pigeon, G. (2013). The Urban Weather Generator. Journal of Building Performance Simulation 6(4), 269-281

Calice, C., Clemente, C., Salvati, A., Palme, M., Inostroza, L. (2017). Urban Heat Island effect on energy consumption of institutional buildings in Rome. IOP Conference Series: Material Sciences and Engineering, 245

Calice, C. (2014). Energy reubrishment in tertiary sector: cases of study and intervention strategies. $\mathrm{PhD}$ Thesis, Sapienza University of Rome

De Santoli, L., Clemente, C., Calice, C., Fraticelli, F. (2012). Guidelines for the retrofit of the school building stock for sustainable urban regeneration in Rome. Proceedings of the7th Conference on Urban Regeneration and Sustainability.

Howard, L. (1860). The Climate of London.
Jenkins, D.P., Peacock, A.D., Banfill, P.F.G. (2009). Will future low-carbon school in UK have an overheating problem? Building and Environment 44 (3), 490-501

Pérez-Lombard, L., Ortiz, J., Pout, C. (2008). A review on buildings energy consumption information. Energy and Buildings 40, 394-398

Menezes, A.C., Cripps, A., Buswell, R.A., Wright, J., Bouchlaghem, D. (2014). Estimating the energy consumption and power demand of small power equipments in office building. Energy and Buildings 75, 199-209

Oke, T. (1982). The energetic bases of urban heat island. Quarterly Journal of the Royal Meteorological Society 109(455), 1-24

Palme, M., Inostroza, L., Villacreses, G., Lobato, A., Carrasco, C. (2017). From urban climate to energy consumption. Enhancing building performance simulation by considering the urban heat island effect. Energy and Buildings 145, 107-120

Palme, M., Inostroza, L., Salvati, A. (2018). Technomass and cooling demand in South America: A super linear relationship? Building Research and Information 46 (8), 864-880

Palme, M., Salvati, A. (2018). UWG-TRNSYS Simulation Coupling for Urban Building Energy Modelling. Building Simulation and Optimization Conference, 11-12 September 2018, Cambridge, UK

Pigeon, G., Legain, D., Durand, P., Masson, V. (2007). Anthropogenic heat release in an old European agglomeration (Touluse, France). International Journal of Climatology 27, 1969-1981

Salvati, A., Coch-Roura, H., Cecere, C. (2016). Urban heat island prediction in the mediterranean context: an evaluation of the urban weather generator model. Architecture, City amd Environment 11(32), 135-156

Sailor, D. (2014). Risks of summertime extreme thermal conditions in buildings as a result of climate change and exacerbation of urban heat islands. Building and Environment 78, 81-88.

Santamouris, M. (2014). On the energy impact of urban heat island and global warming on buildings. Energy and Buildings 82, 100-113.

Toledo, L, Cropper, P., Wright, A. (2016). Unintended consequences of sustainable architecture: Evaluating overheating risk in new dwellings. Proceedings of the Passive and Low Energy Architecture Conference, Los Angeles, USA, July 2016. 